Reihe Ökonomie Economics Series

\title{
On PPP, Unit Roots and Panels
}

Martin Wagner 

Reihe Ökonomie Economics Series

\section{On PPP, Unit Roots and Panels}

Martin Wagner

September 2005

Institut für Höhere Studien (IHS), Wien

Institute for Advanced Studies, Vienna 


\section{Contact:}

Martin Wagner

Department of Economics and Finance

Institute for Advanced Studies

Stumpergasse 56, 1060 Vienna, Austria

孟: $+43 / 1 / 599$ 91-150

fax: $+43 / 1 / 599$ 91-163

email: Martin.Wagner@ihs.ac.at

Founded in 1963 by two prominent Austrians living in exile - the sociologist Paul F. Lazarsfeld and the economist Oskar Morgenstern - with the financial support from the Ford Foundation, the Austrian Federal Ministry of Education and the City of Vienna, the Institute for Advanced Studies (IHS) is the first institution for postgraduate education and research in economics and the social sciences in Austria. The Economics Series presents research done at the Department of Economics and Finance and aims to share "work in progress" in a timely way before formal publication. As usual, authors bear full responsibility for the content of their contributions.

Das Institut für Höhere Studien (IHS) wurde im Jahr 1963 von zwei prominenten Exilösterreichern dem Soziologen Paul F. Lazarsfeld und dem Ökonomen Oskar Morgenstern - mit Hilfe der FordStiftung, des Österreichischen Bundesministeriums für Unterricht und der Stadt Wien gegründet und ist somit die erste nachuniversitäre Lehr- und Forschungsstätte für die Sozial- und Wirtschaftswissenschaften in Österreich. Die Reihe Ökonomie bietet Einblick in die Forschungsarbeit der Abteilung für Ökonomie und Finanzwirtschaft und verfolgt das Ziel, abteilungsinterne Diskussionsbeiträge einer breiteren fachinternen Öffentlichkeit zugänglich zu machen. Die inhaltliche Verantwortung für die veröffentlichten Beiträge liegt bei den Autoren und Autorinnen. 


\section{Abstract}

This paper re-assesses the panel (unit root test) evidence for PPP on four monthly data sets. We discuss and illustrate that commonly-used first generation panel unit root tests are inappropriate for PPP analysis since they are constructed for cross-sectionally uncorrelated panels. Given that real exchange rate panel data sets are - almost by construction - highly cross-sectionally correlated, so called second generation panel unit root methods that allow for and model cross-sectional dependence should be applied. Using inappropriate first generation tests, quite strong evidence for PPP is found. However, this evidence vanishes entirely when resorting to an appropriate method (e.g. the one developed in Bai and $\mathrm{Ng}$, 2004a) for nonstationary cross-sectionally correlated panels. We strongly believe that our findings are relevant beyond the data sets investigated here for illustration.

\section{Keywords}

PPP, real exchange rate index, unit root, panel, cross-sectional dependence, factor model

\section{JEL Classification}

C23, F30, F31 


\section{Comments}

Part of this work has been done whilst visiting the Economics Department of the European University Institute in Florence, whose hospitality is gratefully acknowledged. I thank Chiara Osbat for discussions on the topic and for generously providing the data used in this study. The computations for the second generation methods discussed in Section 2.2 have been performed in MATLAB with programmes based on code made available by Christophe Hurlin. The helpful comments of Jaroslava Hlouskova and Robert Kunst are gratefully acknowledged. The usual disclaimer applies. 


\section{Contents}

1 Introduction 1

2 A Brief Description of the Applied Panel Methods 6

2.1 First Generation Tests ............................................................................... 7

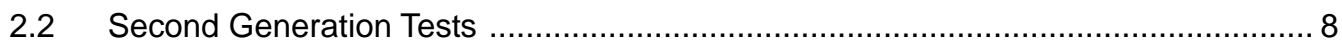

3 Data and Results 10

4 Summary and Conclusions 16

$\begin{array}{ll}\text { References } & 18\end{array}$

$\begin{array}{ll}\text { Appendix } & 23\end{array}$ 



\section{Introduction}

The law of one price holds for a good in a group of countries if its price is the same in all countries when expressed in a common currency. Moving from a single good to a basket of goods various notions of purchasing power parity (PPP) are commonly used. Denote with $\tilde{E}_{i t}$ the exchange rate of country $i$ 's currency to the currency of the base country ${ }^{1}$, with $\tilde{P}_{i t}$ the price of the basket of goods in country $i$ and with $\tilde{P}_{t}^{*}$ the price of the same basket in the base country. The real exchange rate (for the basket of goods chosen) is then defined as

$$
\tilde{Q}_{i t}=\frac{\tilde{E}_{i t} \tilde{P}_{i t}}{\tilde{P}_{t}^{*}}
$$

Commonly-used baskets are consumer goods or tradable goods. Strong PPP is said to hold if the real exchange rate is equal to 1 . Note that, even if the law of one price holds for all goods, strong PPP is only guaranteed to hold if the shares of all goods are identical in all countries' baskets. This is unlikely to be the case and thus it might be useful to study (deviations from) strong PPP at the individual goods level.

There are many reasons why one cannot expect strong PPP to hold. ${ }^{2}$ To name a few: Differences in the composition of the considered baskets of goods (as previously mentioned), non-tradables included in the baskets of goods used to compute real exchange rates, distribution costs (see e.g. Burstein et al., 2004), market imperfections or impediments to trade. Therefore, for empirical applications usually a weak form of PPP is studied: PPP is said to hold for a group of countries in its weak form, if the real exchange rates are stationary. If the modelling framework is one of $\mathrm{I}(1)$ prices and exchange rates, this implies that the deviations from PPP are of a smaller stochastic order than prices and exchange rates themselves. If real exchange rates are stationary with mean equal to 1 , then deviations from the strong PPP level are not persistent and many authors estimate the half-lives of deviations from PPP for stationary real exchange rates. Recent contributions in this spirit are e.g. Cashin and McDermott (2003) or Imbs et al. (2005). The former focuses on median unbiased estimation and the latter studies the effect of aggregation biases on the estimated half-lives. ${ }^{3}$

\footnotetext{
${ }^{1}$ In our applications the base country is the US, thus $\tilde{E}_{i t}$ is given in US-\$ per unit of local currency.

${ }^{2}$ Survey papers on PPP include Froot and Rogoff (1995), Rogoff (1996), Sarno and Taylor (2002) or Taylor (2003).

${ }^{3}$ Unfortunately Imbs et al. (2005) use first generation panel unit root tests for testing the unit root hypothesis. As we argue in this paper these tests are highly misleading in the PPP context. Thus, in a companion paper we re-assess their data set with appropriate second generation panel unit root and stationarity tests, see Wagner (2005). A second problem is that both studies use price index data instead of price data, which
} 
Numerous works that test for the validity of the weak form of PPP have been written in both a time series setting and, more recently, also in a panel setting. ${ }^{4}$ At this point, one should perhaps note that the null hypothesis of stationary real exchange rates is only tested in a minority of these papers, since most use unit root tests (as opposed to stationarity tests) and interpret rejection of the unit root null hypothesis as evidence for stationarity. Thus, these contributions implicitly treat rejection of the null hypothesis as acceptance of the alternative. When basing inference on unit root tests, perhaps only the non-rejection of the null hypothesis should be considered as evidence against PPP. ${ }^{5}$ Several authors have documented that even for long-run data the unit root (and stationarity) tests available suffer from severe size distortions (see Engel, 2000). For this reason over the last several years the focus of the empirical literature has shifted to panel unit root and stationarity tests. Panel tests are commonly thought of suffering from less severe distortions. Whether this is true or not is however not so clear, see Hlouskova and Wagner (2005) for the results of a large scale simulation study that documents substantial size distortions of several commonly used tests even for large panels.

Apart from the time series versus panel unit root test question, a more fundamental problem is the fact that many studies use so called first generation panel unit root tests to test the unit root null for the logarithm of the real exchange rate, i.e. in (with lower case letters denoting logarithms):

$$
\tilde{q}_{i t}=\tilde{e}_{i t}+\tilde{p}_{i t}-\tilde{p}_{t}^{*}
$$

First generation methods (see Section 2.1) rest upon the assumption of cross-sectional independence. This assumption is very unlikely to hold in the context of PPP applications for many reasons. First, the (no arbitrage) arguments underlying the law of one price and PPP rest upon economic relationships of one form or the other between countries. Second, the world economy is becoming ever more integrated and thus shocks can be expected to have impacts on several countries. Third, the very definition of the real exchange rate shows that

implies that the concept of deviation from PPP potentially loses part of its meaning, see the discussion below in this section.

${ }^{4}$ Time series contributions include Engel (2000) and Papell (1997) and early (i.e. first generation) panel contributions include Coakley and Fuertes (1997), Frankel and Rose (1996), Imbs et al. (2005), Lothian (1997), MacDonald (1996), Oh (1996) and Wu (1996). Abuaf and Jorion (1990) is an early important contribution that studies PPP from a multivariate perspective and thus falls neither in the pure time series nor in the panel category.

${ }^{5}$ Also here we present the results of mostly panel unit root tests and only one stationarity test. However, the purpose of this paper is only to address some potential problems when using tests that are likely to be inappropriate. 
for all countries' real exchange rates, the price level of the base country $\left(\tilde{p}_{t}^{*}\right)$ is contained, see (2). This, admittedly obvious, fact implies that generically due to this algebraic reason alone, there will be cross-sectional dependence. ${ }^{6}$

Thus, it is possible that PPP studies using first generation panel unit root and stationarity tests could be misleading. We try to assess this problem by applying first and second generation tests on our data sets and by comparing the results obtained with the different methods. We use the first generation tests developed in Breitung (2000), Levin et al. (2002) and Maddala and $\mathrm{Wu}$ (1999). Furthermore, the first generation panel stationarity test developed by Hadri (2000) is applied.

The problem of cross-sectional correlation has not gone unnoticed in the literature. ${ }^{7}$ O'Connell (1998) is one of the first to note (and illustrate via simulations) that first generation panel unit root tests can be highly distorted for cross-sectionally correlated panels. He uses a GLS approach to correct for cross-sectional correlation. His approach can only handle cross-sectional correlation in the stationary components. This may not be enough, since the presence of the base country price series in all cross-section members indicates the possibility of a common nonstationary component in real exchange rate panels. Lyhagen (2000) studies exactly that situation, with one common stochastic trend and shows that several first generation panel unit root and cointegration tests (including those of Levin et al., 2002 and Im et al., 2003) are severely affected. In particular he shows that the size of the tests is tending to one with increasing cross-sectional dimension. In his simulations he finds serious distortions for panels of cross-sectional dimensions equal to or larger than ten. More recently Bai and $\mathrm{Ng}$ (2004b) combine a factor model approach with panel stationarity and unit root tests to study PPP. They find strong impact of a common stationary component on the real exchange rates of fourteen European countries with the United States as the base country. They furthermore find both stationary and nonstationary de-factored real exchange rates and thus some countries with a stationary real exchange rate and others where the real

\footnotetext{
${ }^{6}$ Note here already that for the four data sets considered in this paper, the cross-sectional correlations are very high, see e.g. Table 5. We consider four monthly data sets with the United States as the base country. The four data sets are the Euro Area countries excluding Ireland, a panel of eleven Central Eastern European countries, a panel of twenty-nine industrial countries and a panel containing fifty-seven non-Euro Area countries, labelled 'World Wide' for simplicity. The variable we use is the CPI based real exchange rate index. The data are described in detail in Section 3.

${ }^{7}$ Besides the ones discussed here other studies discussing cross-sectional correlation and its effects are Banerjee et al. (2005), Caporale and Cerrato (2004) or Choi (2004). Further examples are listed in Table 1 of Choi (2004).
} 
exchange rate is nonstationary. ${ }^{8}$

In this paper we implement a variety of second generation panel unit root tests (all described in Section 2.2). Of the methods implemented, the approach developed in Bai and $\mathrm{Ng}$ (2004a) is the most general and therefore our main findings are based on the results obtained with this methodology. The methodology developed by Bai and Ng (2004a) is the only one available to date that allows for both stationary as well as nonstationary common factors (and offers tests for discriminating the two). Therefore this method appears particularly useful for PPP analysis in a panel context, where as mentioned the base country price level is one candidate for a common nonstationary factor. For completeness we also report the results obtained with several less general second generation tests. These are the tests developed in Chang (2002), Choi (2002), Moon and Perron (2004) and Pesaran (2003). All these methods are restricted to stationary factors or correlation in the stationary components of the panel data generating process (i.e. to short-run correlation only).

In the vast majority of empirical applications (and also in this paper, see the detailed data description in Section 3) the data used are actually not real exchange rates, but real exchange rate indices. This stems from the fact that usually price level series are not available but only price indices (in our data sets these are the consumer price indices). Furthermore we also use nominal exchange rate indices. ${ }^{9}$ Using real exchange rate indices for PPP investigations has a few implications on how the results should be interpreted. This can be seen as follows: Denote with $P_{i t}$ and $P_{t}^{*}$ the price indices in country $i$ and the base country with base period $t_{0}$. Similarly $E_{i t}$ denotes the nominal exchange rate index. Thus, the price indices are (in principle) derived from the price levels via $P_{i t}=100 \frac{\tilde{P}_{i t}}{\tilde{P}_{i t_{0}}}$ and similarly for the base country and the nominal exchange rates. ${ }^{10}$ The logarithm of the real exchange rate index of country $i, q_{i t}$ say, is thus given by

$$
\begin{aligned}
q_{i t} & =e_{i t}+p_{i t}-p_{t}^{*} \\
& =\log 100+\tilde{e}_{i t}-\tilde{e}_{i t_{0}}+\log 100+\tilde{p}_{i t}-\tilde{p}_{i t_{0}}-\log 100-\tilde{p}_{t}^{*}+\tilde{p}_{t_{0}}^{*} \\
& =\log 100+\tilde{q}_{i t}-\tilde{q}_{i t_{0}}
\end{aligned}
$$

\footnotetext{
${ }^{8}$ In our Euro Area data which comprises eleven countries and a different sample period than the data used by Bai and Ng (2004b) we find six nonstationary common factors. The large differences in results show that the methods may be sensitive. Further understanding of the finite sample properties of the Bai and $\mathrm{Ng}$ methodology thus has to be gained.

${ }^{9}$ Using nominal exchange rate indices instead of the nominal exchange rates themselves, which are of course available, is only done to make the real exchange rate indices more comparable in size, since in the base period all real exchange rate indices computed this way equal to 100. The results do not hinge upon this choice.

${ }^{10}$ In our application with monthly data there are actually 12 base periods such that the arithmetic means of $E_{i t}, P_{i t}$ and $P_{t}^{*}$ equal 100 over 1995.
} 
Thus, the difference between the logarithm of the real exchange rate index and the logarithm of the real exchange rate is given by the logarithm of the actual real exchange rate in the base year $\left(\tilde{q}_{i t_{0}}\right)$ plus the logarithm of 100 . The fact that $\tilde{q}_{i t_{0}}$ is unobserved, implies that the (strong) PPP level of real exchange rate indices is undetermined, which is well known. However, using indices also implies that for the weak formulation of PPP as a stationary real exchange rate index, the computation of so called half-lives from PPP is a mislabelling: Suppose the half-life of a deviation from PPP is computed from the following regression $q_{i t}=c+\rho q_{i t_{1}}+u_{i t}$. Then, the estimated autoregressive coefficient $(\hat{\rho})$ is related to the half-life of a deviation from the estimated mean $(\hat{c} /(1-\hat{\rho}))$ of the real exchange rate index. There is no reason that the estimated or for that matter the actual mean of the real exchange rate index are equal to minus the unobserved real exchange rate in the base year (plus log 100). Thus, the estimated half-lives are merely half-lives from the sample mean of the real exchange rate index. In particular one can thus end up estimating - without knowing it - the half-live of a deviation from a constant mean real exchange rate index that is arbitrarily far away from the (strong) PPP level. This very fact, which stems from the basic observation that by using indices one loses the level information, should be kept in mind when using index data for PPP and half-life studies.

This paper is only concerned with discussing unit root and panel unit root inference for panels of real exchange rate (indices). We thus do not investigate other potentially important characteristics of the data generating process that may be relevant for analyzing PPP. These are i.a. heteroskedasticity (see e.g. Cashin and McDermott, 2003)11, nonlinearity (see e.g. Taylor and Peel, 2000), or structural breaks in the data generating process (see e.g. Breitung and Candelon, 2003).

Furthermore this contribution is restricted to a univariate approach to the real exchange rate and PPP. Thus, neither cointegration nor panel cointegration tests of PPP are discussed here. Cointegration tests of PPP basically test for the presence of a cointegrating relationship between the nominal exchange rate and the prices in country $i$ and the base country. There is a huge literature on this approach as well and we only want to note here that the panel cointegration studies are subject to exactly the same problem as the first generation panel unit root tests. I.e. the applied panel cointegration tests are constructed for cross-sectionally

\footnotetext{
${ }^{11}$ These authors also study the impact of median unbiased estimation on half-lives from PPP, with the caveat of using index data as well.
} 
independent panels. Therefore these studies are subject to the same critique that is discussed here for (first generation) panel unit root studies of PPP.

The main findings can be briefly summarized as follows: Individual time series unit root tests do not lead to a rejection of the null hypothesis for a majority of countries (in all four country sets). For the Euro Area countries and the data set comprising twenty-nine industrial countries no rejection at all occurs. With first generation panel unit root tests, quite some rejections of the unit root null hypothesis occur. For the CEEC and the World Wide data set all test except for the test developed by Breitung (2000) lead to a rejection of the unit root null hypothesis. For the Euro Area data set a majority of tests leads to a rejection of the unit root null at the $10 \%$ critical level. The evidence is quite mixed and depends upon the chosen test. ${ }^{12}$ The methodology of Bai and Ng (2004a) leads to the following results. For all four data sets several (between four and six) common factors are found, which are furthermore all classified as nonstationary. These findings imply that we do not find support of the PPP hypothesis from a panel perspective, once we allow for nonstationary common factors. The interpretation of these nonstationary common factors is an interesting question beyond the scope of this paper. Note for completeness that the panel unit root tests on the idiosyncratic components lead to a rejection of the unit root null hypothesis for the CEEC and Industrial countries data sets.

The paper is organized as follows: In Section 2 the applied econometric methods are described. In Section 3 the data and results are presented and Section 4 briefly summarizes and concludes. An appendix containing tables with country lists for the two larger data sets follows the main text.

\section{A Brief Description of the Applied Panel Methods}

In this section we briefly describe the applied panel unit root tests. The first sub-section describes tests designed for cross-sectionally independent panels (first generation tests) and methods that allow for cross-sectional dependence (second generation tests) are discussed in the second subsection.

The time series unit root test results displayed are obtained by applying the augmented

\footnotetext{
${ }^{12}$ The stationarity test of Hadri (2000) leads to rejection of the null of stationarity for all data sets. Thus, the findings of first generation unit root and stationarity tests are not 'consistent' with each other. It is, however, known (see e.g. Hlouskova and Wagner, 2005) that the Hadri test tends to incorrectly reject the null hypothesis for serially correlated but stationary series.
} 
Dickey-Fuller (ADF) test with lag lengths chosen according to BIC and a constant included. ${ }^{13}$

\subsection{First Generation Tests}

Denote with $q_{i t}$ again the logarithm of the real exchange rate index, for which we want to test the null hypothesis $H_{0}: \rho_{i}=1$ for all $i=1, \ldots, N$ in

$$
q_{i t}=\rho_{i} q_{i t-1}+\alpha_{i}+u_{i t}
$$

where $u_{i t}$ are stationary processes assumed to be cross-sectionally independent for the first generation tests. ${ }^{14}$ The tests applied differ with respect to the alternative hypothesis. The homogenous alternative is given by $H_{1}^{1}: \rho_{i}=\rho<1$ for $i=1, \ldots, N$. The heterogeneous alternative is given by $H_{1}^{2}: \rho_{i}<1$ for $i=1, \ldots, N_{1}$ and $\rho_{i}=1$ for $i=N_{1}+1, \ldots, N .{ }^{15}$ For PPP applications it is not clear which of the alternatives is the more 'relevant' one. The first alternative implies that all real exchange rates have to be stationary whereas the latter allows for a fraction of the real exchange rates to be integrated. Individual unit root tests for our data sets indicate that the majority of series appears to be nonstationary and only a minority appears to be stationary. Thus, for our application the heterogenous alternative may be more adequate.

In general, some correction for serial correlation in $u_{i t}$ is necessary. Two main approaches are followed in all tests, either a non-parametric correction in the spirit of Phillips and Perron (1988) or the parametric correction in the spirit of the augmented Dickey Fuller (ADF) test. The ADF correction adds lagged differences of the variable $\left(\Delta q_{i t-j}\right)$ to the regression to achieve serially uncorrelated errors.

The following tests have been implemented: The test of Levin et al. (2002) (LLC), which is a pooled ADF test after suitable first step corrections. The second is the test of Breitung (2000) (Bre), which is a pooled ADF type test based on a simple variable transformation to avoid the necessity of bias correction factors. These two tests, due to their pooled estimation of $\rho$, test against the homogenous alternative. We have implemented three tests with the heterogeneous alternative. One is the test of Im et al. (2003), which is essentially the groupmean of individual ADF t-statistics (IPS). The two other tests against the heterogeneous

\footnotetext{
${ }^{13}$ Results obtained from computations including both constants and linear trends are available from the author upon request.

${ }^{14}$ Note that also time effects $\theta_{t}$ and/or linear time trends $\gamma_{i} t$ can be included. The corresponding results are available from the author upon request. For panel PPP applications, however, the usual specification seems to include only fixed effects $\alpha_{i}$.

${ }^{15}$ With $\lim _{N \rightarrow \infty} \frac{N_{1}}{N}>0$.
} 
alternative are based on the Fisher (1932) principle. Fisher uses the fact that under the null hypothesis the $p$-values of continuous test statistics are uniformly distributed over the unit interval. This implies that minus two times the logarithm of the $p$-values is $\chi_{2}^{2}$ distributed. Thus, the sum of $N$ independent transformed $p$-values is $\chi_{2 N}^{2}$ distributed. For unit root testing in cross-sectionally independent panels this idea has been employed by Maddala and Wu (1999) and Choi (2001). The difference between these two approaches is that Choi (2001) establishes asymptotic normality in $N$ by applying appropriate scaling factors. Note that in principle any time series unit root test can be applied to the individual series. We follow Maddala and Wu (1999) and use the ADF and the Phillips and Perron (1988) unit root tests (labelled $M W_{A D F}$ and $M W_{P P}$ henceforth). ${ }^{16}$

For completeness (i.e. to flip null and alternative hypothesis) we also implement the panel stationarity test of Hadri (2000) ( $\mathrm{Had}$ ), which is a panel extension of the Kwiatkowski et al. (1992) test. Simulation studies, see e.g. Hlouskova and Wagner (2005), show that this test suffers from severe size distortions whenever the series exhibit sizeable serial correlation.

The test results presented are all based on including an intercept, i.e. fixed effects, only and with the (individual specific) lag lengths chosen according to BIC. Further results, e.g. including also trends or different lag length selection procedures are available upon request. All long-run variance estimators are based on the Bartlett kernel with window-length choice according to Newey and West (1994).

\subsection{Second Generation Tests}

The discussion in the introduction has made clear that allowing for cross-sectional dependence may be of prime importance when using panel unit root tests for studying PPP. Several tests that allow for cross-sectional dependence have been developed in the literature.

We start our discussion with factor model based approaches, and go from the most general to the most restricted. In a factor model the cross-sectional dependence enters through common factors $\left(F_{t} \in \mathbb{R}^{k}\right)$ that are loaded $\left(\lambda_{i} \in \mathbb{R}^{k}\right)$ in the individual real exchange rates

$$
q_{i t}=\rho_{i} q_{i t-1}+\alpha_{i}+\lambda_{i}^{\prime} F_{t}+u_{i t}
$$

where the stationary processes $u_{i t}$ are again assumed to be cross-sectionally independent and $k$ denotes the number of common factors. The most general results have been obtained by

\footnotetext{
${ }^{16}$ Note that applying the test of Choi (2001) results in the same test decisions as with the Maddala and Wu type tests for all four data sets.
} 
Bai and Ng (2004a). First, their results allow to determine the number of common factors $(N o C F)$ via several information criteria (see Bai and $\mathrm{Ng}, 2002$ ), where both stationary and integrated factors are feasible. Our results concerning the number of factors are based on their information criterion $\mathrm{AIC}_{3} \cdot{ }^{17}$ Second, they develop tests for the number of common trends contained in the common factors. The two tests $\left(C T\right.$ and $\left.C T_{A R}\right)$ follow Stock and Watson (1988) and the difference between them is that the second test is based on a vectorautoregression for the common factors. In case only one common factor is found, a unit root test on the single estimated common factor is available. Third, they propose panel unit root tests based on the Fisher principle on the de-factored data, i.e. on the observations from which the estimated factor component has been subtracted. By assumption and construction the de-factored observations are (asymptotically) cross-sectionally independent and thus first generation type tests are applicable for them. Bai and $\mathrm{Ng}$ (2004a) present one test following Choi (2001) $\left(B N_{N}\right)$ and one test following Maddala and $\mathrm{Wu}(1999)\left(B N_{\chi^{2}}\right)$.

Moon and Perron (2004) develop a factor model based panel unit root test similar to Bai and Ng (2004a). However, there are two important differences. First, they only present a panel unit root test on de-factored data and do not develop inference for the common factors. The estimation of the common factors is similar in spirit to Bai and $\mathrm{Ng}$ (2004a) and the number of common factors is determined using again the Bai and $\mathrm{Ng}$ (2002) information criterion $\mathrm{AIC}_{3}$. Second, Moon and Perron (2004) assume that all common factors are stationary. This is potentially too strong a restriction in the PPP context, given the above discussion. Moon and Perron (2004) develop two t-type tests to test for a panel unit root in the de-factored data $\left(M P_{a}, M P_{b}\right)$. The two tests differ with respect to the variance and serial correlation corrections applied. For estimating the long-run variances the Bartlett kernel with window length chosen according to Newey and West (1994) is applied.

Pesaran (2003) provides an extension of the Im et al. (2003) test to allow for one stationary factor with heterogeneous loadings. His procedure, which is a suitably cross-sectionally augmented IPS (CIPS) augmented Dickey Fuller type test, is based on including cross-section averages of the level and of lagged differences to the IPS-type regression. The limiting distribution of this test is non-standard and tables with critical values are given in Pesaran (2003).

Choi (2002) presents test statistics based on a two-way error component model. This

\footnotetext{
${ }^{17}$ This criterion displayed the best performance in several simulations run by the author.
} 
model structure can, equivalently, be interpreted as a factor model with one factor and identical loadings for all units (and country specific effects). His tests are based on eliminating the deterministic components and the cross-sectional correlations by applying cross-sectional demeaning and GLS detrending in the spirit of Elliott et al. (1996). Based on these preliminary steps Choi proposes three group-mean tests based on the Fisher test principle, which differ in scaling and aggregation of the $p$-values of the individual tests. All three test statistics, $C_{p}$, $C_{Z}$ and $C_{L^{*}}$, are asymptotically standard normally distributed. The time series unit root test used in the implementation of these tests is the augmented Dickey-Fuller test.

A different approach to handle cross-sectional correlation is developed in Chang (2002). She presents panel unit root tests that handle short-run cross-sectional correlation by applying nonlinear instrumental variable estimation of the (usual) individual augmented Dickey-Fuller regressions. ${ }^{18}$ The instruments are given by integrable functions of the lagged levels of the variable and the test statistic is given by an appropriately standardized sum of the individual $t$-statistics. We present the results for three different instrument generating functions, termed $N L_{i}$ for $i=1,2,3$. Im and Pesaran (2003) show that the asymptotic behavior established in Chang (2002) only holds for $N \ln T / \sqrt{T} \rightarrow 0$, which suggests that $N$ is required very small compared to $T$ in practice. Note that this approach poses few restrictions on the shape of the correlation between the panel members, but is restricted to correlation in the stationary components.

\section{$3 \quad$ Data and Results}

We use four monthly data sets, with time series dimension between 136 and 280 observations and cross-sectional dimension between 11 and 57. Especially the longer series thus may also be suitable for individual time series unit root testing. The data span and the corresponding panel dimensions are given in Table 1.

The Euro Area data set, see Table 2, consists of only eleven instead of twelve countries, since Ireland is missing due to data availability problems. The Euro Area data set ends in December 1998. This date is chosen since the Euro was introduced as national currency at the beginning of 1999, with the exception of Greece. ${ }^{19}$ The results of Table 2 show that the ADF test does not lead to a rejection of the unit root null hypothesis for any country in this

\footnotetext{
${ }^{18}$ By short-run we mean here that the stationary processes $u_{i t}$ in our notation are allowed to be correlated.

${ }^{19}$ Physically the Euro changeover took place at the beginning of 2002.
} 


\begin{tabular}{|r|c|c|c|c|}
\hline & Start & End & $T$ & $N$ \\
\hline \hline Euro Area & $1980 / 1$ & $1998 / 12$ & 228 & 11 \\
CEEC & $1993 / 1$ & $2004 / 6$ & 136 & 11 \\
Industrial & $1980 / 1$ & $1998 / 12$ & 228 & 29 \\
World Wide & $1981 / 1$ & $2004 / 4$ & 280 & 57 \\
\hline
\end{tabular}

Table 1: Time periods and panel dimensions of the four considered monthly data sets. $T$ denotes the number of observations over time and $N$ denotes the cross-sectional dimension.

\begin{tabular}{|l|l|l|l|}
\hline Austria & France & Italy & Portugal \\
Belgium & Germany & Luxembourg & Spain \\
Finland & Greece & Netherlands & \\
\hline
\end{tabular}

Table 2: Euro Area countries excluding Ireland. The null hypothesis of a unit root is not rejected for any country. The time series unit root test results are based on the ADF test with lag lengths chosen according to BIC.

group.

The second data set contains eleven Central Eastern European countries (CEECs), see Table 3, from January 1993 to June 2004. The start date of this country group is chosen to exclude the period of very high inflation at the beginning of transition. The unit root null hypothesis is rejected at the $5 \%$ critical level for Estonia, Latvia, Lithuania and Romania. That the null hypothesis is rejected for the three Baltic countries, may probably be explained for Lithuania and Latvia by the currency board arrangements with respect to the US- $\$$ respectively the SDR that have been in place over part of the sample period. For Estonia the result is a bit more surprising, given that there a currency board with respect to first the DM and then the Euro has been in place.

Country lists and unit root test results for the two other data sets considered, 'Industrial' and 'World Wide', are contained in the appendix in Tables 8 and 9. In the former twenty-nine industrial countries are included and the latter is in fact constructed by including all fiftyseven countries for which monthly series back to January 1981 are available and which are not members of the Euro Area. For the Industrial data set the unit root null is not rejected for any country and in the World Wide data set rejections occur for fourteen out of fifty-seven countries (at the $10 \%$ level).

Several countries are contained in both data sets. Since the sample periods differ between the two data sets, the individual unit root test results do not always coincide. E.g. for Turkey 


\begin{tabular}{|l|l|l|l|}
\hline Albania & Estonia & Lithuania & Slovak Rep. \\
Bulgaria & Hungary & Poland & Slovenia \\
Czech Rep. & Latvia & Romania & \\
\hline
\end{tabular}

Table 3: Central Eastern European countries (CEEC). 'Bold' entries indicate rejection of the unit root hypothesis at the $5 \%$ critical level. The time series unit root test results are based on the ADF test with lag lengths chosen according to BIC.

the unit root null hypothesis is rejected at the $5 \%$ critical level in the World Wide data set but is not rejected in the Industrial data set. This example also shows again that unit root test results are sensitive to sample choice, the difference here being one year at the beginning of the sample and about five and a half years at the end of the sample.

We now turn to panel unit root analysis and start in Table 4 with the first generation results. For the CEEC and the World Wide data sets all tests except for the test of Breitung (2000) reject the unit root null hypothesis at the 5\% level. For the Euro Area data three of five tests reject the null hypothesis at $10 \%$. Here the two tests that do not lead to a rejection are the Maddala and Wu (1999) type tests. Finally for the Industrial country data set only the Breitung (2000) and Im et al. (2003) test lead to a rejection of the unit root null hypothesis. Thus, an often made claim in the literature, namely that panel methods have to be applied because of the low power of time series unit root tests, appears to be corroborated by these findings, given that time series unit root tests lead to a rejection of the unit root hypothesis in only a minority of countries in all four data sets. There is some rough correspondence between the time series and the first generation panel results. For the data sets where the unit root hypothesis is not rejected for any country with the ADF test, i.e. the Euro Area and the Industrial countries, the first generation panel unit root tests lead to rejection of the null by fewer tests than for the two other data sets. Note also that tests with the homogenous and the heterogeneous alternative reject the null hypothesis for all four data sets.

The quite strong evidence against the unit root null hypothesis is not really consistent with the time series evidence. This non-consistency is, however, in line with the findings of Lyhagen (2000), who shows that first generation panel unit root tests tend to reject the null hypothesis with increasing probability (tending to 1) for cross-sectionally highly correlated panels. We therefore use second generation methods to assess whether the first generation findings can indeed be explained by cross-sectional dependence.

The last column of Table 4 shows that the panel stationarity test of Hadri (2000) leads to 


\begin{tabular}{|r|cc|ccc||c|}
\hline & $L L C$ & Bre & $I P S$ & $M W_{A D F}$ & $M W_{P P}$ & Had \\
\hline \hline Euro Area & -1.31 & -1.37 & -1.34 & 24.65 & 23.30 & $\mathbf{1 2 . 7 9}$ \\
CEEC & $\mathbf{- 8 . 8 7}$ & -0.58 & $\mathbf{- 4 . 1 7}$ & $\mathbf{9 8 . 6 9}$ & $\mathbf{1 4 9 . 7 3}$ & $\mathbf{1 4 . 5 2}$ \\
Industrial & -1.04 & $\mathbf{- 2 . 4 9}$ & $\mathbf{- 1 . 7 3}$ & 66.10 & 65.54 & $\mathbf{2 2 . 6 8}$ \\
World Wide & $\mathbf{- 7 . 1 3}$ & 1.13 & $\mathbf{- 6 . 6 0}$ & $\mathbf{2 8 1 . 3 8}$ & $\mathbf{2 1 4 . 5 4}$ & $\mathbf{5 1 . 7 0}$ \\
\hline
\end{tabular}

Table 4: Results of first generation panel unit root and stationarity tests. 'Bold' entries indicate rejection of the unit root hypothesis at the $5 \%$ critical level and 'italic' entries indicate rejection at the $10 \%$ level.

a rejection of the null of stationarity for all four data sets. Thus, opposing results are obtained from a panel stationarity test and from the panel unit root tests. However, that the Hadri test findings are in a sense consistent with the results of individual unit root tests, which result in a non-rejection of the null hypothesis for a majority of countries. Given that the null hypothesis of the Hadri test is stationarity in all series, the rejection of the null hypothesis for all four data sets is not in conflict with the individual unit root test results.

All results displayed in Table 4 are obtained with methods that rely - as has been discussed - upon cross-sectional independence. The discussion in the introduction indicates that this assumption is unlikely to hold. One easy way of verifying the validity of this assumption is to compute the correlation matrix of the first differences of the real exchange rates. Taking first differences is necessary since at least some of the series are likely nonstationary. Due to the fact that the differenced series exhibit serial correlation the covariance matrix has to be estimated by some appropriate method. We estimate the covariance matrix of the differenced series by using the Bartlett kernel with a window length of four, chosen according to Newey and West (1994). The results are rather clear: All the real exchange rate (differentials) are highly correlated, see Table 5 for the Euro Area data. ${ }^{20}$ Similar tables are also available upon request for (subsets of) the other data sets.

The high correlations imply that second generation methods have to be applied in order to study the unit root properties of the data. Given that there are no a priori reasons to believe that the cross-sectional dependence is restricted to stationary components the appropriate method to use is that of Bai and $\mathrm{Ng}$ (2004a). We display the results obtained with this approach in Table 6. For all data sets common factors, which are furthermore

\footnotetext{
${ }^{20}$ In principle testing whether the non-diagonal entries of the estimated variance matrix are all equal to zero is required to decide about cross-sectional correlation. However, any such test will clearly reject the null hypothesis of no correlation, given that the correlations vary between 0.72 and 1.
} 


\begin{tabular}{|c|ccccccccccc|}
\hline & AUT & BEL & FIN & FRA & GER & GRE & ITA & LUX & NED & POR & ESP \\
\hline AUT & 1.00 & 0.97 & 0.79 & 0.97 & 0.99 & 0.83 & 0.87 & 0.97 & 0.99 & 0.86 & 0.87 \\
BEL & & 1.00 & 0.78 & 0.97 & 0.97 & 0.84 & 0.86 & 1.00 & 0.97 & 0.85 & 0.87 \\
FIN & & & 1.00 & 0.80 & 0.78 & 0.72 & 0.80 & 0.78 & 0.78 & 0.77 & 0.81 \\
FRA & & & & 1.00 & 0.97 & 0.83 & 0.88 & 0.97 & 0.97 & 0.89 & 0.88 \\
GER & & & & & 1.00 & 0.84 & 0.86 & 0.98 & 0.99 & 0.86 & 0.87 \\
GRE & & & & & & 1.00 & 0.78 & 0.83 & 0.85 & 0.78 & 0.83 \\
ITA & & & & & & & 1.00 & 0.85 & 0.86 & 0.83 & 0.86 \\
LUX & & & & & & & & 1.00 & 0.97 & 0.86 & 0.87 \\
NED & & & & & & & & & 1.00 & 0.84 & 0.87 \\
POR & & & & & & & & & & 1.00 & 0.88 \\
ESP & & & & & & & & & & & 1.00 \\
\hline
\end{tabular}

Table 5: Correlation matrix of the first differences of the logarithms of the Euro Area real exchange rate indices. The correlations are based on the estimated (long-run) covariance matrix estimated with the Bartlett kernel with window length four, chosen according to Newey and West (1994).

all classified as nonstationary, are found. However, the number of these factors appears to be estimated imprecisely, with e.g. six common factors for the Euro Area data and five for the CEEC data, which both comprise only eleven countries. ${ }^{21}$ For the Industrial country data, which contain the eleven Euro Area countries, only four common factors are found. In principle this may happen, but it more likely indicates poor small sample properties of the information criteria used to determine the number of common factors. The properties of these information criteria have to be studied in more detail, given that the estimation of the space spanned by the common factors is consistent only for both $T$ and $N$ diverging to infinity. However, and compare also again the numbers in Table 5, irrespective of the exact number of common factors, cross sectional correlation is prominent in our data sets. The second common observation for all data sets is, as already indicated, that all common factors are classified as nonstationary. Concerning the idiosyncratic components, for the CEEC and Industrial country data sets the panel unit root tests $\left(B N_{N}\right.$ and $\left.B N_{\chi^{2}}\right)$ lead to a rejection of the unit root null hypothesis and for the other two data sets the null hypothesis is not rejected (see columns 3 and 4 in Table 6). Thus, from a second generation panel perspective we do not find evidence for stationarity in the real exchange rate indices. Hence, indeed, applying

\footnotetext{
${ }^{21}$ Bai and $\mathrm{Ng}$ (2004b) also study real exchange rates for European countries, with a different sample composition and period. They find evidence for one common stationary factor in a panel comprising fourteen countries. Thus, indeed it appears that the methodology is quite sensitive. These issues have to be studied in detail, most likely also by simulation methods, which is beyond the scope of the present paper.
} 


\begin{tabular}{|r|c|c|c||c|c|}
\hline & $N o C F$ & $B N_{N}$ & $B N_{\chi^{2}}$ & $N o C T$ & $N o C T_{A R}$ \\
\hline \hline Euro Area & 6 & 0.32 & 24.11 & 6 & 6 \\
CEEC & 5 & $\mathbf{1 . 7 3}$ & 33.44 & 5 & 5 \\
Industrial & 4 & $\mathbf{2 . 5 4}$ & $\mathbf{8 5 . 3 6}$ & 4 & 4 \\
World Wide & 4 & -0.10 & 112.52 & 4 & 4 \\
\hline
\end{tabular}

Table 6: Results of Bai and Ng (2004a) PANIC analysis. NoCF indicates the estimated number of common factors according to $\mathrm{AIC}_{3} . \quad B N_{N}$ and $B N_{\chi^{2}}$ denote the Bai and $\mathrm{Ng}$ unit root tests on the de-factored data. $N o C T$ and $N o C T_{A R}$ denote the number common trends within the common factors found with the two tests discussed in the text. 'Bold' entries indicate significance of test statistics at the $5 \%$ critical level and 'italic' entries indicate rejection at the $10 \%$ level.

first generation methods leads to an overly optimistic assessment concerning stationarity of real exchange rates.

One possible next step is to test whether the observed potential common factor (the base country price index) is contained in the space spanned by the estimated unobserved factors. However, to date such a test has not been developed to the author's knowledge. Bai and Ng (2004c) address this question only in a stationary context, where the observed potential factor, the common factors and the idiosyncratic components are all assumed stationary. In principle one could use their approach for the first differences of the real exchange rate data, but we abstain from doing so, since we believe that it is more fruitful to address the relationship between potential and estimated unobserved factors for the integrated data themselves.

For completeness we report in Table 7 the panel unit root test results obtained with the other second generation tests described in Section 2.2. Note again that the presence of nonstationary common factors implies that all these tests, which allow only for stationary common factor(s) or correlation in the innovations, are applied in a situation for which they are not developed. It may, however, still be worthwhile to see what kind of results one obtains with them (given that it furthermore is, see the discussion above, also possible that the Bai and $\mathrm{Ng}$ tests are distorted in finite samples). With the tests developed by Moon and Perron (2004) and Choi (2001) the unit root null hypothesis is rejected for all data sets. The test of Pesaran (2003) leads to a rejection for the CEEC and World Wide data sets. Thus, using these second generation tests one can 'resurrect' PPP. However, these tests have been constructed under relatively stringent assumptions, which are not supported by the Bai and Ng (2004a) results. The tests of Moon and Perron (2004) are designed for stationary factors and the tests 


\begin{tabular}{|r|cc|c|ccc|ccc|}
\hline & $M P_{a}$ & $M P_{b}$ & $C I P S$ & $C_{p}$ & $C_{Z}$ & $C_{L^{*}}$ & $N L_{1}$ & $N L_{2}$ & $N L_{3}$ \\
\hline \hline Euro Area & $\mathbf{- 9 . 6 7}$ & $\mathbf{- 4 . 8 8}$ & $\mathbf{- 2 . 1 5}$ & $\mathbf{5 . 5 4}$ & $\mathbf{- 4 . 8 4}$ & $\mathbf{- 4 . 7 2}$ & 1.54 & -0.07 & 3.31 \\
CEEC & $\mathbf{- 1 2 . 4 4}$ & $\mathbf{- 7 . 8 6}$ & $\mathbf{- 3 . 4 9}$ & $\mathbf{1 2 . 0 3}$ & $\mathbf{- 6 . 2 1}$ & $\mathbf{- 7 . 8 7}$ & 1.63 & 3.39 & 1.67 \\
Industrial & $\mathbf{- 1 5 . 8 2}$ & $\mathbf{- 6 . 6 3}$ & $\mathbf{- 1 . 8 9}$ & $\mathbf{8 . 7 4}$ & $\mathbf{- 7 . 4 5}$ & $\mathbf{- 7 . 3 3}$ & 1.78 & 1.68 & 3.84 \\
World Wide & $\mathbf{- 2 0 . 7 7}$ & $\mathbf{- 9 . 3 7}$ & $\mathbf{- 2 . 6 1}$ & $\mathbf{1 9 . 6 5}$ & $\mathbf{- 1 3 . 3 0}$ & $\mathbf{- 1 4 . 5 5}$ & 0.24 & 6.41 & 3.49 \\
\hline
\end{tabular}

Table 7: Results of second generation panel unit root tests. Bold entries indicate significance of test statistics at the $5 \%$ critical level.

of Pesaran (2003) and of Choi (2002) only allow for one stationary factor (with furthermore identical loadings in the tests of Choi, 2002). Therefore, given the Bai and $\mathrm{Ng}$ results, the results obtained with these methods appear highly dubious, being obtained on data sets that are unlikely to fulfill the necessary assumptions.

The tests of Chang (2002) lead to a rejection of the unit root null hypothesis throughout. However, also these tests are only designed for data sets with stationary common components and furthermore also the comment of Im and Pesaran (2003) applies.

Summing up, we find no evidence for stationarity in real exchange rates from a second generation panel perspective when resorting to the Bai and $\mathrm{Ng}$ (2004a) methodology. With the other second generation methods the results are mixed, but all these methods are not applicable if the results obtained with the Bai and $\mathrm{Ng}$ (2004a) methodology are correct. The Bai and Ng (2004a) methodology based findings imply in particular the presence of nonstationary common factors. This can explain why we find support for the PPP hypothesis when using first generation panel unit root tests.

\section{Summary and Conclusions}

In this paper we have re-assessed the panel evidence for PPP by comparing the results obtained with both first and second generation panel unit root methods on four monthly real exchange rate panel data sets. Following the literature PPP is sloppily said to hold if the unit root null hypothesis is rejected for a panel of real exchange rate series.

Our discussion concerning cross-sectional dependence (e.g. the base country price index) and our empirical findings of strong cross-country correlations of the real exchange rates for all our four data sets, indicate that the results obtained with the usually applied first generation methods may be misleading. First generation panel unit root and stationarity tests are designed for cross-sectionally uncorrelated panels. For cross-sectionally correlated 
panels so called second generation methods have to be applied. Most second generation methods are based on factor models, where the cross-sectional dependence is modelled due to one or more common factors.

Prior to panel analysis we test the time series individually for unit roots. The ADF test leads to a rejection of the unit root null hypothesis only for a minority of the series in each of the four data sets and for no series at all in two of the data sets. Thus, from a time series perspective, the evidence for PPP appears to be weak. This is a usual finding that actually has fostered a lot of panel based empirical work on PPP, with the usual argument being that time series unit root test results are poor due to low power of unit root tests.

Several authors (see e.g. Lyhagen, 2000) have shown that cross-sectional correlation in the form of e.g. common (nonstationary) factors biases first generation tests even asymptotically. The bias is in the direction that the null hypothesis of a unit root is rejected too often (i.e. the size diverges to 1 for $N \rightarrow \infty$ ), and thus 'too strong' evidence for PPP is often found. This result is consistent with the findings we obtain with first generation tests: For each of the data sets between two and four of the applied five first generation panel unit root tests lead to a rejection of the unit root null hypothesis.

With the methodology developed in Bai and Ng (2004a) we, however, find no evidence for PPP for any of our four data sets. The method of Bai and Ng (2004a) is particularly useful for studying PPP: It allows for both stationary and integrated common factors, provides tests for discriminating between stationary and integrated factors and offers panel unit root tests for the de-factored observations. For all four data sets we find several common factors, which are all classified as nonstationary. The number of estimated factors is likely estimated imprecisely, with e.g. six common nonstationary factors for the panel of eleven Euro Area countries. With this method we find no evidence for PPP, as in each real exchange rate the common nonstationary factors are loaded. The idiosyncratic components appear to be stationary for CEEC and Industrial data sets and nonstationary for the Euro Area and World Wide data sets.

For completeness also several more restricted second generation methods are applied, which deliver mixed evidence. However, these other methods are all developed for more restrictive situations than allowed for in the Bai and $\mathrm{Ng}$ (2004a) set-up, e.g. they all allow only for stationary common factors or correlation only in the innovations. Therefore the results obtained with the Bai and $\mathrm{Ng}$ (2004a) methodology are the most relevant findings 
from a panel perspective. What remains to be done in future work is to study in more detail the finite sample performance of the Bai and Ng (2004a) methods. In particular the properties of the estimation procedures for the number of common factors has to be investigated in more detail to strengthen the support for our clear findings that suggest non-validity of PPP.

A second line of discussion in this paper is related to the observation that most studies, also this one, use real exchange rate indices instead of real exchange rates. This is due to the fact that usually no price series but only price index series are available. For our data sets these are the consumer price indices. We argue in Section 1 that estimating half-lives based on index data is a void exercise, since the computed half-lives are nothing but estimates of half-lives of deviations from the sample mean of the real exchange rate index (in case the real exchange rate index is stationary). Thus, such half-lives are in particular not distinguishable from half-lives towards real exchange rate levels that are arbitrarily far away from PPP (and that may include persistent price differentials). This limitation should probably be made more explicit in the empirical literature.

\section{References}

Abuaf, N., Jorion, P., 1990. Purchasing power parity in the long run. Journal of Finance 45, $157-174$.

Bai, J., Ng, S., 2002. Determining the number of factors in approximate factor models. Econometrica $70,191-221$.

Bai, J., Ng, S., 2004a. A PANIC attack on unit roots and cointegration. Econometrica 72, $1127-1178$.

Bai, J., Ng, S., 2004b. A new look at panel testing of stationarity and the PPP hypothesis, forthcoming in Andrews, D.W.K., Stock, J.H. (Eds.), Identification and Inference in Econometric Models: Essays in Honor of Thomas. J. Rothenberg. Cambridge University Press, Cambridge.

Bai, J., Ng, S., 2004c. Evaluating latent and observed factors in macroeconomics and finance. Mimeo.

Banerjee, A., Marcellino, M., Osbat, C., 2005. Testing for PPP: Should we use panel methods. Empirical Economics 30, 77-91. 
Breitung, J., 2000. The local power of some unit root tests for panel data, in Baltagi, B.H. (Ed.), Nonstationary Panels, Panel Cointegration, and Dynamic Panels. Elsevier, Amsterdam, pp. 161-177.

Breitung, J., Candelon, B., 2003. Purchasing power parity during currency crises: A panel unit root test under structural break. University of Bonn, Discussion Paper.

Burstein, A., Eichenbaum, M., Rebelo, S., 2004. Large devaluations and the real exchange rate. Forthcoming in Journal of Political Economy.

Caporale, G.M., Cerrato, M. 2004. Panel tests of PPP: A critical overview. Institute for Advanced Studies, Economics Series No. 159.

Cashin, P., McDermott, C.J., 2003. An unbiased appraisal of PPP. IMF Staff Papers 50.

Chang, Y., 2002. Nonlinear IV unit root tests in panels with cross-sectional dependency. Journal of Econometrics 110, 261-292.

Choi, I., 2001. Unit root tests for panel data. Journal of International Money and Finance $20,249-272$.

Choi, I., 2002. Combination unit root tests for cross-sectionally correlated panels, forthcoming in: Corbae, D., Durlauf, S., Hansen, B. (Eds.) Econometric Theory and Practice: Frontiers of Analysis and Applied Research: Essays in Honor of Peter C. B. Phillips. Cambridge University Press, Cambridge.

Choi, C.-Y., 2004. Searching for evidence of long-run PPP from a post-Bretton Woods panel: Separating the wheat from the chaff. Journal of International Money and Finance 23, $1159-1186$.

Coakley, J., Fuertes, A.M., 1997. New panel unit root tests of PPP. Economics Letters 57, $17-22$.

Elliott, G., Rothenberg, T.J., Stock, J.H., 1996. Efficient tests for an autoregressive unit root. Econometrica 64, 813-836.

Engel, C., 1999. Accounting for US real exchange rate changes. Journal of Political Economy $107,507-538$. 
Engel, C., 2000. Long-run PPP may not hold after all. Journal of International Economics $51,243-273$.

Fisher, R.A., 1932. Statistical Methods for Research Workers. Oliver and Boyd, Edinburgh.

Frankel, J.A., Rose, A.K., 1996. A panel project on purchasing power parity: Mean reversion within and between countries. Journal of International Economics 40, 209-224.

Froot, K.A., Rogoff, K., 1995. Perspectives on PPP and long-run real exchange rates, in Grossman, G., Rogoff, K. (Eds.) Handbook of International Economics. North-Holland, Amsterdam.

Hadri, K., 2000. Testing for stationarity in heterogeneous panel data. Econometrics Journal $3,148-161$.

Hlouskova, J., Wagner, M., 2005. The performance of panel unit root and stationarity tests: Results from a large scale simulation study. Submitted to Econometric Reviews.

Im, K.S., Pesaran, M.H., 2003. On the panel unit root tests using nonlinear instrumental variables. Mimeo, University of Cambridge.

Im, K.S., Pesaran, M.H., Shin, Y., 2003. Testing for unit roots in heterogeneous panels. Journal of Econometrics 115, 53-74.

Imbs, J., Mumtaz, H., Ravn, M.O., Rey, H., 2005. PPP strikes back: Aggregation and the real exchange rate. Quarterly Journal of Economics 120, 1-43.

Kwiatkowski, D., Phillips, P.C.B., Schmidt, P., Shin, Y., 1992. Testing the null hypothesis of stationarity against the alternative of a unit root. Journal of Econometrics 54, 91-115.

Levin, A., Lin, C.F., Chu, C-S.J., 2002. Unit root tests in panel data: Asymptotic and finite sample properties. Journal of Econometrics 108, 1-22.

Lothian, J.R., 1997. Multi-country evidence on the behavior of purchasing power parity under the current float. Journal of International Money and Finance 16, 19-35.

Lyhagen, J., 2000. Why not use standard panel unit root tests for testing PPP. Working Paper, Stockholm School of Economics. 
MacDonald, R., 1996. Panel unit root tests and real exchange rates. Economics Letters 50, $7-11$.

Maddala, G.S., Wu, S., 1999. A Comparative study of unit root tests with panel data and a simple new test. Oxford Bulletin of Economics and Statistics 61, 631-652.

Moon, H.R., Perron, B., 2004. Testing for a unit root in panels with dynamic factors. Journal of Econometrics 122, 81-126.

Newey, W., West, K.D., 1994. Automatic lag selection for covariance matrix estimation. Review of Economic Studies 61, 631-653.

O'Connell, P.G.J., 1998. The overvaluation of purchasing power parity. Journal of International Economics 44, 1-19.

Oh, K.-Y., 1996. Purchasing power parity and unit root tests using panel data. Journal of International Money and Finance 15, 405-418.

Papell, D.H., 1997. Searching for stationarity: Purchasing power parity under the current float. Journal of International Economics 43, 313-332.

Papell, D.H., Theodoridis, H., 2001. The choice of numeraire currency in panel tests of purchasing power parity. Journal of Money, Credit and Banking 33, 790-803.

Pesaran, M.H., 2003. A simple panel unit root test in the presence of cross section dependence. Mimeo, University of Cambridge.

Phillips, P.C.B., Perron, P., 1988. Testing for a unit root in time series regression. Biometrika $75,335-346$.

Rogoff, K., 1996. The purchasing power parity puzzle. Journal of Economic Literature 34, $647-668$.

Sarno, L., Taylor, M.P., 2002. Purchasing power parity and the real exchange rate. IMF Staff Papers 49, 65-105.

Stock, J.H., Watson, M.W., 1988. Testing for common trends. Journal of the American Statistical Association 83, 1097 - 1107.

Taylor, M.P., 2003. Purchasing power parity. Review of International Economics 11, 436-452. 
Taylor, M.P., Peel, D.A., 2000. Non-linear adjustment, long-run equilibrium and exchange rate fundamentals. Journal of International Money and Finance 19, 33-53.

Wagner, M., 2005. A look at the Imbs et al. (2005) data from a 2nd generation panel unit root perspective. Mimeo.

Wu, X., 1996. Are real exchange rates nonstationary? Evidence from a panel-data test. Journal of Money, Credit and Banking 28, 54-61. 


\section{Appendix: Country Lists for 'Industrial' and 'World Wide' Data Sets}

In the following tables a 'bold' entry indicates rejection of the individual unit root hypothesis at the $5 \%$ critical level and an 'italic' entry indicates rejection at the $10 \%$ critical level. The time series unit root test results are based on the augmented Dickey-Fuller test with intercepts included and lag lengths chosen according to BIC.

\begin{tabular}{|l|l|l|l|}
\hline Argentina & Germany & Malaysia & South Africa \\
Austria & Greece & Mexico & Spain \\
Belgium & Indonesia & Netherlands & Sweden \\
Brazil & Italy & Norway & Switzerland \\
Canada & Japan & Philippines & Thailand \\
Denmark & Korea & Portugal & Turkey \\
Finland & Luxembourg & Singapore & United Kingdom \\
France & & & \\
\hline
\end{tabular}

Table 8: Industrial countries.

\begin{tabular}{|l|l|l|l|}
\hline Algeria & Dominican Rep. & Kenya & Samoa \\
Argentina & Ecuador & Korea & Saudi Arabia \\
Bahamas & Egypt & Madagascar & Senegal \\
Bolivia & El Salvador & Malaysia & Seychelles \\
Botswana & Fiji & Malta & Singapore \\
Brazil & Ghana & Mauritius & South Africa \\
Burkina Faso & Guatemala & Mexico & Swaziland \\
Burundi & Haiti & Morocco & Sweden \\
Canada & Honduras & Niger & Switzerland \\
Chile & Hong Kong & Norway & Thailand \\
Colombia & India & Pakistan & Turkey \\
Costa Rica & Indonesia & Paraguay & United Kingdom \\
Cote d'Ivoire & Israel & Peru & Uruguay \\
Cyprus & Japan & Philippines & Venezuela \\
Denmark & & & \\
\hline
\end{tabular}

Table 9: World wide country set excluding Euro Area countries. 

Author: Martin Wagner

Title: On PPP, Unit Roots and Panels

Reihe Ökonomie / Economics Series 176

Editor: Robert M. Kunst (Econometrics)

Associate Editors: Walter Fisher (Macroeconomics), Klaus Ritzberger (Microeconomics)

ISSN: 1605-7996

(C) 2005 by the Department of Economics and Finance, Institute for Advanced Studies (IHS),

Stumpergasse 56, A-1060 Vienna • ㅍㅛㅛ +43 1 59991-0 • Fax +43 1 59991-555 • http://www.ihs.ac.at 
ISSN: 1605-7996 